\title{
Thermal Expansion Measurements in Fresh and Saline Ice Using Fiber Optic Strain Gauges and Multipoint Temperature Sensors Based on Bragg Gratings
}

\author{
Aleksey Marchenko, ${ }^{1}$ Ben Lishman, ${ }^{2}$ David Wrangborg, ${ }^{1}$ and Torsten Thiel ${ }^{3}$ \\ ${ }^{1}$ The University Centre in Svalbard, 9171 Longyearbyen, Norway \\ ${ }^{2}$ Institute for Risk and Disaster Reduction, University College London, London WC1E6BT, UK \\ ${ }^{3}$ Advanced Optics Solutions (AOS) GmbH, 01139 Dresden, Germany \\ Correspondence should be addressed to Aleksey Marchenko; aleksey.marchenko@unis.no
}

Received 22 November 2015; Revised 9 February 2016; Accepted 14 February 2016

Academic Editor: Xingwei Wang

Copyright ( 2016 Aleksey Marchenko et al. This is an open access article distributed under the Creative Commons Attribution License, which permits unrestricted use, distribution, and reproduction in any medium, provided the original work is properly cited.

\begin{abstract}
This paper describes the use of Fiber Bragg Grating (FBG) sensors to investigate the thermomechanical properties of saline ice. FBG sensors allowed laboratory measurements of thermal expansion of ice samples with a range of different sizes and geometries. The high sampling frequency, accuracy, and resolution of the FBG sensors provide good quality data across a temperature range from $0^{\circ} \mathrm{C}$ to $-20^{\circ} \mathrm{C}$. Negative values of the effective coefficient of thermal expansion were observed in ice samples with salinities $6 \mathrm{ppt}, 8 \mathrm{ppt}$, and $9.4 \mathrm{ppt}$. A model is formulated under which structural transformations in the ice, caused by temperature changes, can lead to brine transfer from closed pockets to permeable channels, and vice versa. This model is compared to experimental data. Further, in experiments with confined floating ice, heating as well as thermal expansion due to vertical migration of liquid brine, caused by under-ice water pressure, was observed.
\end{abstract}

\section{Introduction}

Saline ice is a composite material, a solid ice matrix containing liquid and gas inclusions, with a structure which changes under the influence of thermal and mechanical loads. Saline ice consists of pure ice grains, grouped in columns or platelets, and brine pockets and channels. It has been thought that sea ice is impermeable to brine transport when the liquid brine content is less than $5 \%$ and is permeable when the brine content is greater than 5\% [1]. In fact, sea ice always contains porous channels, and liquid brine can migrate through these under the influence of pressure gradients [2]. Thermal changes influence the permeability of sea ice significantly, as brine freezes into ice on cooling, and ice melts into water on heating. Thus the final state of a saline ice sample subjected to thermal changes is determined not only by initial and final conditions but also by the history of temporal variations and salt fluxes at the boundaries. This means that the thermomechanical properties of saline ice samples depend on their size and geometry.

Fresh ice and brine both exhibit typical thermal behavior: they expand when heated and contract when cooled. Saline ice, however, can behave atypically because of phase changes. When brine freezes, this leads to a mean density reduction (since ice is less dense than water), and so cooling can lead to expansion. Similarly, and by the inverse process, heating can lead to contraction. This unusual behavior of saline ice was studied in laboratory experiments and described by Pettersson [3] and Malmgren [4]. Their experiments were conducted by immersing a sea ice sample in fluid and measuring the changes in fluid volume as the sample temperature changed. Fluid volume changes were then used to calculate thermal volume expansion coefficients. Johnson and Metzner [5] note that this procedure assumes that no additional fluid is added to the volume of the immersion fluid. This assumption has been found to be invalid, since brine can 
leak out of the sample and be expelled into the immersion fluid.

Theoretical models for the calculation of the coefficient of thermal expansion of saline ice have been developed by Malmgren [4] and Cox [6]. Malmgren and Cox made opposing assumptions when formulating the basic equations. Malmgren assumed that brine is never expelled from the sample and that all salts are trapped in brine pockets inside the sample. Temperature changes therefore cause internal ice melt or brine refreezing. Cox, contrastingly, assumed that the behavior of saline ice is analogous to a pure ice cup filled with liquid brine: both are free to expand and contract independently, and hence phase changes have no effect on the thermal expansion of the ice.

Johnson and Metzner [5] used a Michelson Interferometer to measure linear thermal expansion of cylindrical ice samples taken from a sheet of first-year congelation sea ice in Harrison Bay, Alaska. Their apparatus included the interferometer along with a sample holder, temperature control unit, and computer-controlled data acquisition unit. The diameter of their samples was $38 \mathrm{~mm}$ and the length was $71.25 \mathrm{~mm}$ for $2 \mathrm{ppt}$ ice and $69.33 \mathrm{~mm}$ for $4 \mathrm{ppt}$ ice. Optically flat target mirrors were frozen to the front surface of the samples, trimmed parallel with a microtome, and used to control the sample length with the interferometer. They were able to achieve a displacement resolution of $316.4 \mathrm{~nm}$, corresponding to a strain resolution of the order of $5 \times 10^{-6}$.

Mean and instantaneous values of the thermal expansion coefficient were found to be similar to the fresh ice thermal expansion coefficient of $5 \times 10^{-5} /{ }^{\circ} \mathrm{C}$. Their 4 ppt ice showed hysteresis when cooled and rewarmed after the initial warming test. Similar effects were observed in the experiments of Butkovich [7] with fresh water ice, where the coefficient of linear thermal expansion decreased with succeeding runs. Their conclusion was that their results agreed with the analysis of Cox [6].

Systematic investigations of the thermomechanical behavior of saline ice samples were performed, using fiber optic strain and temperature sensors based on Fiber Bragg Gratings, in the cold laboratories of the University Centre in Svalbard, Norway, and University College London, UK, from 2012 to 2015 [8-11]. The FBG system used was designed by Advance Optic Solutions GmbH (Germany). The flexibility of the FBG system allowed experiments to be conducted with many different sizes and geometries of ice sample, and with floating ice.

The present paper describes the instrumentation and experimental setups and summarizes experimental results on the measurement of thermal expansion of saline ice. We formulate a new model of the thermal expansion of saline ice, assuming the possibility of structural changes in the ice associated with gradual transformation of closed brine pockets into permeable brine channels, under the influence of temperature changes. Mass changes in the ice with closed brine pockets are estimated using the experimental data. Thermal expansion of saline ice caused by the migration of liquid brine through the ice is also discussed in the paper.

\section{Instrumentation}

The fiber type used for this kind of optical sensing is typically standard telecom single-mode fibers (SMF) that are widely used in communications, with an overall diameter of $0.25 \mathrm{~mm}$ and a core diameter of only about $0.01 \mathrm{~mm}$. A Fiber Bragg Grating is a periodical index change in the refractive index $n$ along this optical silica fiber's core, formed by an interference pattern of two UV laser beams that the fiber is exposed to. There are various techniques to generate the two coherent beams (Figure 1(a)) [12]. The index change results from a certain photosensitivity of the fiber's core which is due to the presence of some chemical dopants inside the silica's structure, typically germanium oxide. The interference pattern being generated by two coherent laser beams consists of a periodic UV power modulation along the fiber determined by the incident angle of the two beams. This UV pattern migrates to the fiber core's index change pattern, by the said photosensitive mechanism.

Areas of higher $n$ alternate with areas of lower $n$ with a period of less than $10^{-6} \mathrm{~mm}$ while $\Delta n$ is relatively small quantity $(\Delta n<0.001$ and $n=1.45)$. Due to the index change, each "grating line" reflects a very small portion of the light wave propagating along the fiber, back to the light source. Although a single reflected portion is negligible compared to the transmitted power, the effect becomes noticeable because the amount of "grating lines" in a conventional FBG is about $4000 / \mathrm{mm}$, and a typical FBG with $10 \mathrm{~mm}$ length consists of 40 thousand reflections. If the light's wavelength matches the condition

$$
\lambda_{\text {Bragg }}=2 \cdot n_{\mathrm{eff}} \cdot \Lambda,
$$

where $n_{\mathrm{eff}}$ is the fiber's effective index, $\lambda_{\mathrm{Bragg}}$ is the light's wavelength, and $\Lambda$ is the index change's period, then all reflected light wave portions are propagating "in-phase" and interfere constructively. Depending on the actual $\Delta n$, this results in a typical narrow-band power peak in the reflection spectrum at $\lambda_{\text {Bragg, }}$, and vice versa in a loss in transmission (Figure 1(b)). According to (1), the reflected wavelength changes with modifying either $n_{\text {eff }}$ or $\Lambda$.

It is easy to see that $\lambda_{\text {Bragg }}$ will change when the fiber is strained or compressed (Figure 1(c)), whereas the effective refractive index is a material property and thus $n_{\text {eff }}$ is sensitive to changes in temperature. This sensitivity of the peak wavelength with respect to thermal and mechanical loads allows the usage of FBG as strain and temperature sensors $[12,13]$. This is now a common field of optical sensing. Several features make the FBG system highly appropriate for geophysical measurements $[14,15]$. These features include

(i) long-term zero-point stability due to the inscribed physical structure;

(ii) transmission of the sensor's signal over distances up to tens of miles;

(iii) a form factor which allows FBG to be embedded into structures;

(iv) good immunity against electromagnetic radiation; 


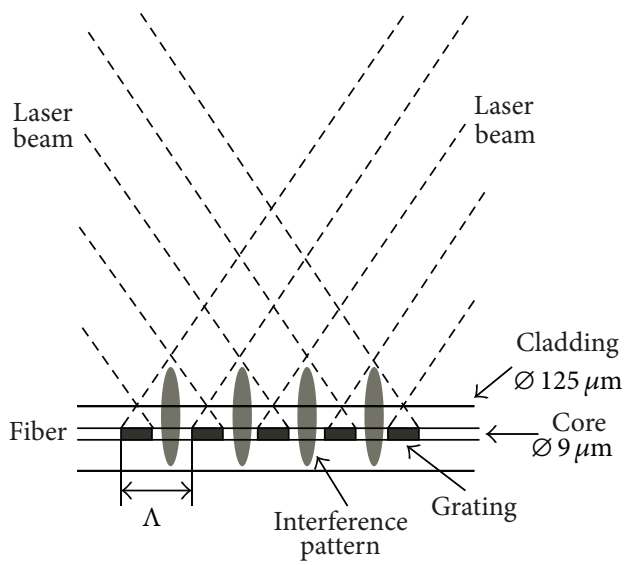

(a)

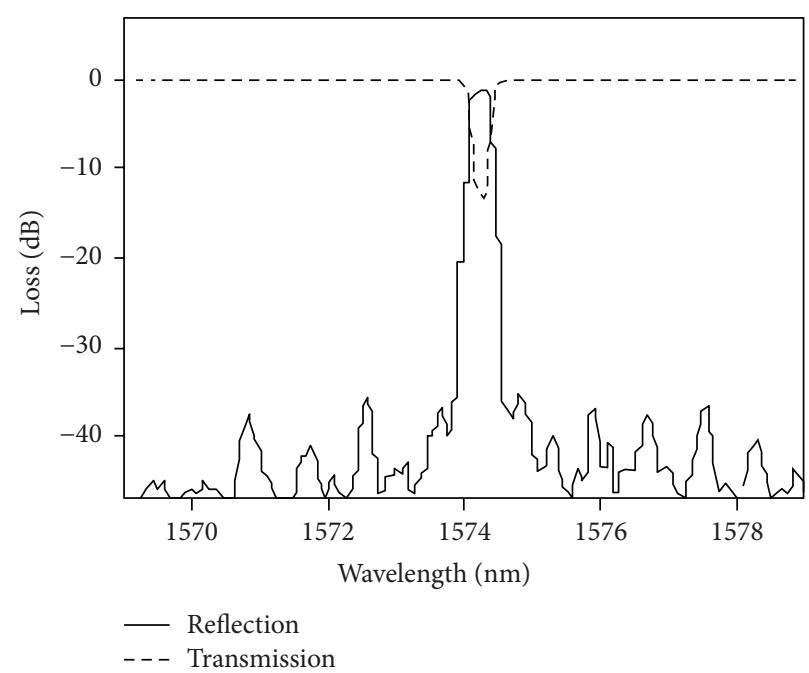

(b)

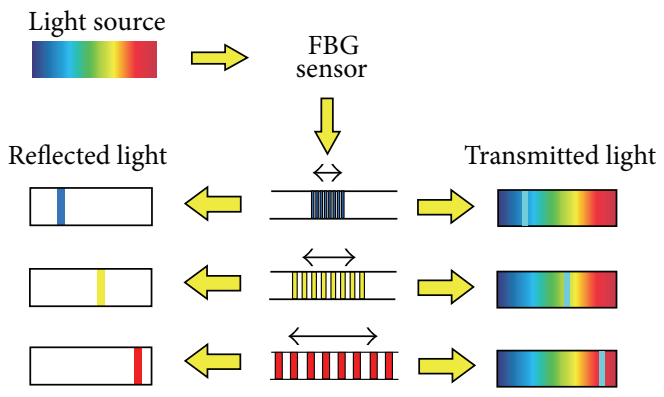

(c)

FIGURE 1: Interference pattern of laser beams in the fiber core during FBG generation (a). Reflected and transmitted signals after the passing of broad band light travelling along the fiber with an FBG inside (b) and a simplified illustration of the strain detection mechanism with a broad band light source containing a continuous spectrum of wavelengths (i.e., colours).

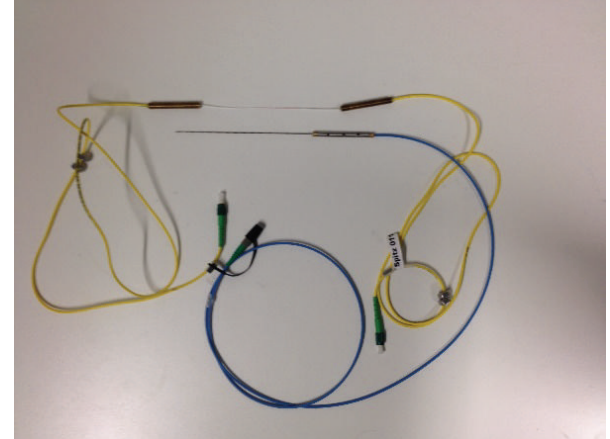

Figure 2: An FBG thermistor string and strain sensor.

(v) ability to cascade and multiplex large numbers of sensors in a network, with a lower complexity than with electrical equivalents.

In our experiment, $\mathrm{FBG}$ sensors are practical for measuring the thermal expansion of large samples because, in contrast to standard dilatometers, the fiber can be embedded directly inside the ice sample. An FBG thermistor string with 12 distributed thermistors and strain sensor are shown in Figure 2.
The neighbour thermistors extend from each other on $1 \mathrm{~cm}$ distance. Typical strain resolution for FBG systems is $10^{-6}$ $(1 \mu$ strain $)$ or better, and the accuracy is typically $5 \cdot 10^{-6}$ ( $5 \mu$ strain). These characteristics are comparable to Michelson Interferometer Laser Dilatometers as used by Johnson and Metzner [5] and discussed above.

The variation $\left(\Delta \lambda_{\text {Bragg }}\right)$ of the peak wavelength caused by the extension $(\Delta L / L)$ and the change of the temperature $(\Delta T)$ of the sensor is described by the equation

$$
\frac{\Delta \lambda}{\lambda}=\mathrm{GF} \cdot \frac{\Delta L}{L}+T K \cdot \Delta T,
$$

where the gauge factor GF $=0.719$ and a linear temperature coefficient $T K=5.5 \cdot 10^{-6}$ are the constants obtained from a calibration cycle for our FBG sensors in standard SMF fiber, within a temperature range from $-20^{\circ} \mathrm{C}$ to $0^{\circ} \mathrm{C}$.

The variation of the peak wavelength $\Delta \lambda$ is measured with a spectrometer that receives the reflected signal from the FBG sensor. For the calculation of the strain $(\Delta L / L)$ according to formula (2) it is necessary to measure the temperature change $(\Delta T)$ at the strain sensor's position in order to compensate $T K$. The temperature measurements can easily be performed with another FBG sensor protected 


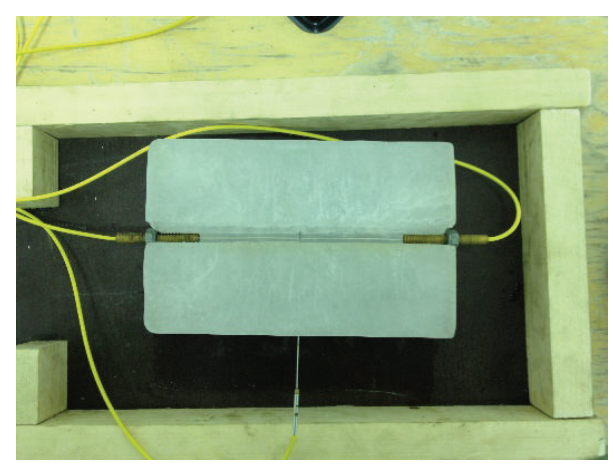

(a)

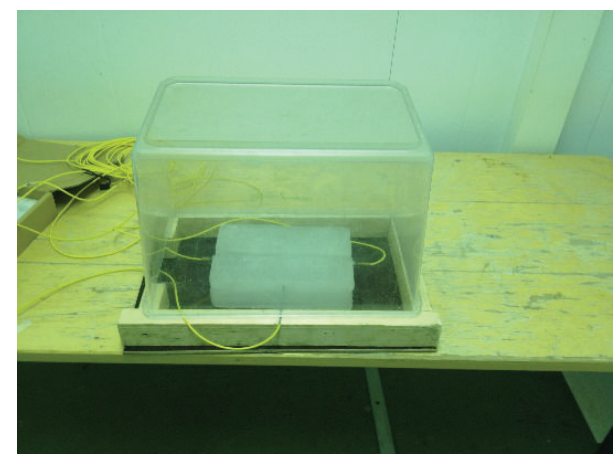

(b)

FIGURE 3: Installation of FBG strain sensor and thermistor string in ice sample (a). Ice sample inside plastic housing (b).

from mechanical deformation, or alternatively with a thermometer. In our experiments, we used FBG strain sensors with a reference peak wavelength in the vicinity of around $1534 \mathrm{~nm}$ and FBG temperature sensors with a reference peak wavelength in the vicinity of around $1565 \mathrm{~nm}$. The strain and temperature sensors were cascaded in one optical fiber. The FBG measurement system's nominal resolution and accuracy in our experiment were $0.08^{\circ} \mathrm{C}$ and $0.4^{\circ} \mathrm{C}$, respectively.

\section{Experiments}

3.1. Thermal Expansion of Unconfined Ice. Experiments were performed in the cold laboratory of the University Centre in Svalbard (UNIS). Ice was formed in the UNIS ice tank from a mixture of sea water, pumped from a nearby fjord, and fresh water. The salinity of the ice samples varied from 0 to $10 \mathrm{ppt}$, and the ice had columnar structure. The ice samples had a rectangular shape, with the long dimension around $20 \mathrm{~cm}$ and the shorter dimensions $5-10 \mathrm{~cm}$. The optical fibers with FBG strain sensors had an integrative working length of $20 \mathrm{~cm}$ that was defined by two brass anchor bolts with nuts and washers. The optical fibers were placed into $2 \mathrm{~mm}$ wide cuts that were sawn in the ice samples and were fastened at the edges of the ice samples with nuts and washers (Figure 3(a)). The ice block's thermal expansion or shrinkage is therefore transferred to the optical fiber with the FBG inside (this fiber is prestrained to around $0.3 \%$ by adjusting the nuts accordingly). The FBG fiber was not frozen into place, since this would allow localized shear around the FBG itself to distort the measurements. The FBG temperature sensor (thermistor string with 12 thermistors) was encapsulated in a $1 \mathrm{~mm}$ stainless steel capillary tube and inserted into a drilled hole in the ice sample so that one thermistor registered air temperature near the FBG strain sensor. Other thermistors measured temperature inside the ice sample.

The equipment used in our measurement setup includes a broadband SLED light source with a central wavelength of $1550 \mathrm{~nm}$ and a bandwidth (FWHM) of $\sim 90 \mathrm{~nm}$ (AOS GmbH, Germany), a NIR spectrometer "I-MON 512E-USB 2.0 interrogation monitor" with a detectable spectral width of 1510-1595 nm (Ibsen Photonics S/A, Denmark), a PC, and two FBG sensors, one for strain measurement and

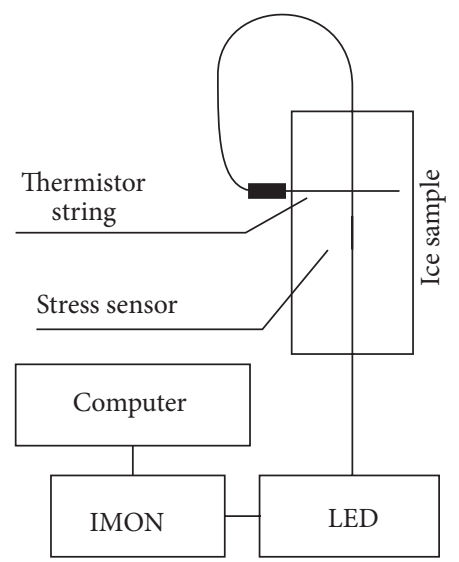

FIGURE 4: Schematic of experiment for measuring of thermal expansion.

one for temperature measurement (both from AOS GmbH, Germany). The Ibsen monitor is distributed with operating software, including a LabView source code. The experimental schematic is shown in Figure 4. All electronic devices, the LED source, the spectrometer, and the PC, were installed outside the cold laboratory. Regular optical single-mode cables were used to connect the equipment to the FBG sensors embedded into the ice sample in the cold laboratory.

The ice sample was covered by a plastic housing to avoid evaporation (Figure 3(b)). The temperature in the cold laboratory $(2.5 \times 2.5 \times 1.8 \mathrm{~m})$ was changed in increments of $2^{\circ} \mathrm{C}$ from $-20^{\circ} \mathrm{C}$ to a nominal $0^{\circ} \mathrm{C}$, programmed, and displayed on the laboratory's control system. Temperature control is provided by a Frigobase Carel system with temperature precision better than $1^{\circ} \mathrm{C}$ and set point resolution of $0.1^{\circ} \mathrm{C}$. Time intervals for the temperature increments were set to 2 hours or greater. Temperature and extension are measured at $1 \mathrm{sample/s.} \mathrm{During} \mathrm{the} \mathrm{experiment,} \mathrm{we} \mathrm{realized} \mathrm{that} \mathrm{the}$ actual air temperature close to the ice samples was lower than the displayed temperature by several degrees. We therefore switched off the cooling system to allow the room to warm, resulting in maximal environmental temperature of $-3^{\circ} \mathrm{C}$.

Ice salinity was measured with a Mettler Toledo Seven Pro conductivity meter SG7, with resolution $0.01 \mathrm{ppt}$. The 
salinity of the ice samples was measured before and after the experiments. In some experiments, multiple "dummy" samples are kept under the same conditions as the straingauged sample: these samples can then be used to measure changes in salinity during the experiments.

3.2. Thermal Expansion of Confined Ice. A series of experiments were undertaken in the cold rooms of University College London. The FBG strain sensor was used to measure the linear strain in ice samples of cylindrical shape under various conditions. The ice was formed between two steel pipes: an outer pipe with inside diameter of $11 \mathrm{~cm}$ and an inner pipe with outside diameter of $2 \mathrm{~cm}$. Fresh ice was made from London tap water; saline ice was made from the same, with $8 \mathrm{ppt} \mathrm{NaCl}$ added. The samples were formed in layers, so that up to $1 \mathrm{~cm}$ depth of water was added and allowed to freeze before the next layer was formed. No evidence was seen of supercooled water or large bubbles within these layers. The experiments are conducted in air.

Ice samples were tested in three conditions: unconstrained, constrained within one pipe, and constrained between two pipes (in the first two cases, pipes were removed after forming by briefly warming). These conditions are illustrated in Figure 5. The pipe has length of $180 \mathrm{~mm}$, and the samples are milled $5 \mathrm{~mm}$ from either end of the pipe, such that the initial ice sample has two flat parallel ends $190 \mathrm{~mm}$ apart. On these flat ends we place an aluminium spacer of width of $4 \mathrm{~mm}$ which supports the FBG strain sensor, so that expansion in the ice in the along-pipe $(z)$ direction stretches the sensor.

Temperatures are measured using the FBG 12-thermistor string inserted through a drilled hole in the ice (or ice and pipe), such that temperatures are recorded through the sample in the $x$-direction. The temperature used for calibration of the strain sensor is that closest to the sensor, in this case, thermistor 7. For calculation of thermal expansion, we use the average of thermistors $1-5$, which gives a mean value through the ice but eliminates the thermistors in the air, which respond much faster to temperature changes in the room. Temperature and extension are measured at 1 sample/s. The entire apparatus is shown in a photograph in Figure 6.

3.3. Thermal Expansion of Floating Confined Ice. Laboratory experiments were conducted in the UNIS cold lab ice tank to investigate the possibility of ice expansion under the influence of under-ice water pressure, without external heating or cooling. This physical mechanism is not discussed in the scientific literature. It can occur when liquid brine migrates through the ice from a relatively warm region to a relatively cold region under the influence of a pressure gradient. Lateral confinement provides a vertically directed shear force at the ice edges. This shear force is in balance with the pressure force applied to the ice bottom (Figure 7(a)).

Saline ice of $8 \mathrm{~cm}$ thickness was frozen on the surface of sea water of $1 \mathrm{~m}$ depth with initial salinity $12 \mathrm{ppt}$. The ice salinity was about $6 \mathrm{ppt}$. The ice was not floating in hydrostatic equilibrium, because it cohered to the tank walls. Overpressure in the tank was created by gradually pumping air into a submerged car inner tube using an electrical pump.
The pump was powered by a laboratory power supply with variable voltage so that the pumping speed could be regulated (Figure 7(a)). The increase of water pressure in the tank caused ice creep in the vertical direction. However, our main interest was in measuring any extension or compression of the ice in the horizontal plane.

This extension or compression in the horizontal plane was measured with one FBG fiber optic strain sensor mounted on steel angle brackets frozen into the ice (Figures 7(b) and 8(a)). Another FBG strain sensor was mounted on similar brackets fixed to the tank wall (Figures 7(b) and 8(a)). This sensor recorded deformation of the tank wall under ice action. The FBG thermistor string was used to measure temperature in the air above the ice and the temperature profile in the ice. A temperature and pressure sensor SBE-39 was used to record water pressure below the ice during the experiment. The resolution of the pressure measurements was $4 \cdot 10^{-4} \mathrm{dbar}$. All sensors were synchronized and provided measurements with sampling interval of $1 \mathrm{~s}$.

\section{Results of Experimental Studies}

4.1. Thermal Expansion of Unconfined Ice. Temperature variations in the cold laboratory cause the ice to expand and contract. The laboratory temperature is programmed into an external controller, and three programs are used:

(i) In the first, the control temperature is changed by $2^{\circ} \mathrm{C}$ every 2-3 hours or rarely, over a period of several days. These are referred to as long-term tests.

(ii) In the second, the control temperature is changed by $15-20^{\circ} \mathrm{C}$ up and down in each test twice. These tests take 4-6 hours and are referred to as short-term tests.

(iii) In the third set, the room temperature began at $-20^{\circ} \mathrm{C}$, and the cooling system was then switched off. This led to an increase in temperature which was more monotonic than the other tests (where the cooling system caused sinusoidal temperature fluctuations about a long-term trend). These tests take 8 hours and are referred to as monotonic tests.

The coefficient of volumetric thermal expansion (VCTE) of a material is determined by the formula

$$
\kappa=\frac{1}{\delta V} \frac{d \delta V}{d T},
$$

where $\delta V$ is the infinitesimal volume of the material and $d \delta V$ is a change of the volume caused by the temperature change from $T$ to $T+d T$. If the sample mass $\delta m=\rho \delta V$ is conserved, definition (3) can be formulated as

$$
\kappa=-\frac{1}{\rho} \frac{d \rho}{d T} .
$$

VCTE of fresh ice is calculated with formula (4) where the ice density is calculated by the formula [16]

$$
\rho_{i}=916.8\left(1+1.53 \cdot 10^{-4} T\right)^{-1}\left(\mathrm{~kg} / \mathrm{m}^{3}\right) .
$$




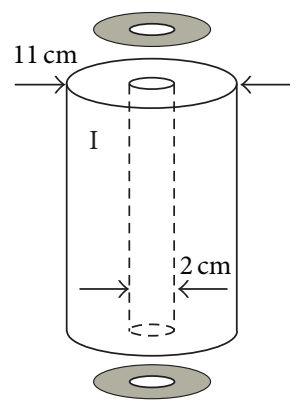

(a)

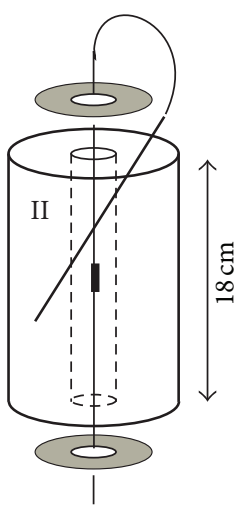

(b)

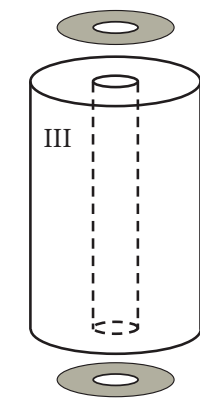

(c)

FIGURE 5: Schematic of experimental configurations: unconstrained ice sample (a); toroidal ice sample constrained by external steel pipe and free to expand into central cavity (b); toroidal ice sample constrained by external and internal steel pipes (c).
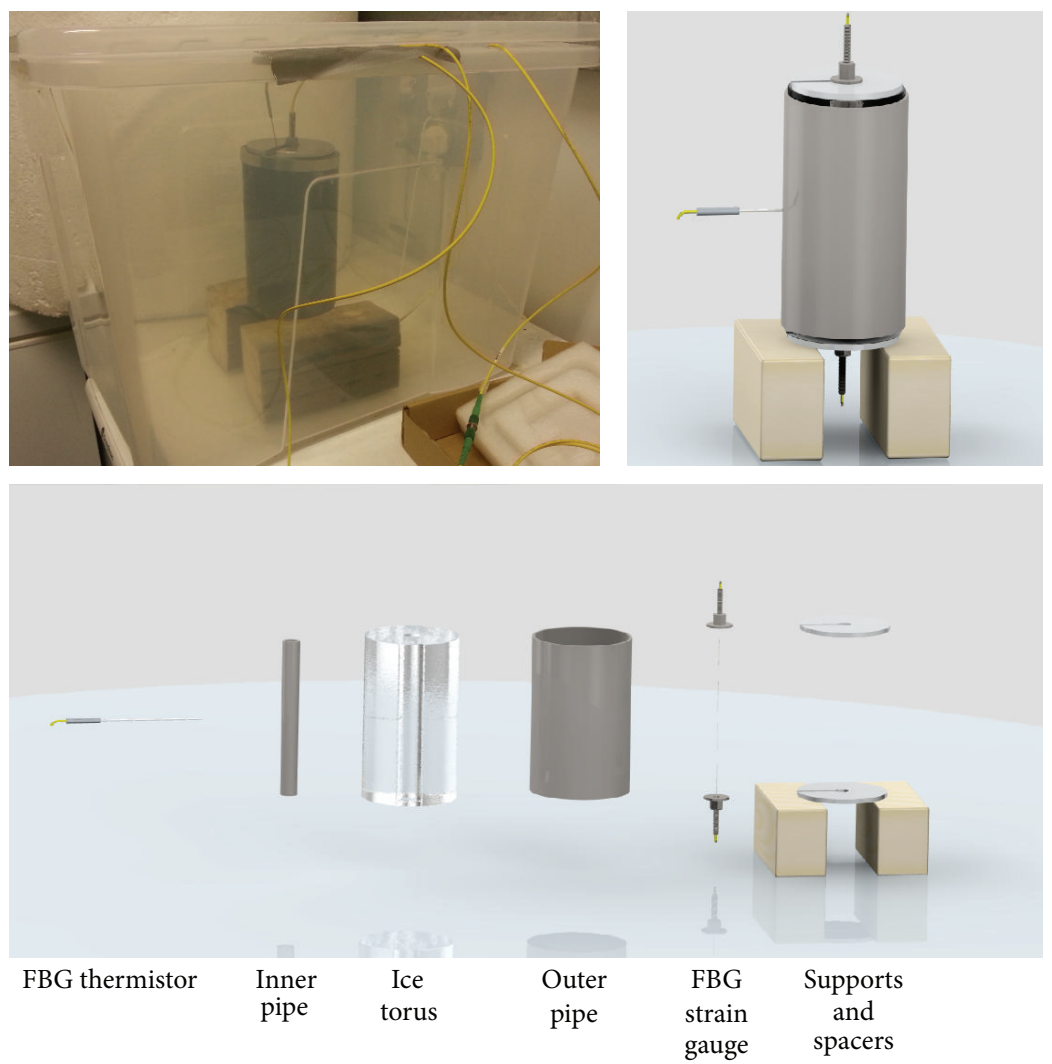

FIGURE 6: Full experiment photo, schematic, and exploded schematic.

VCTE of fresh ice is around $1.53 \cdot 10^{-4} \mathrm{~K}^{-1}$. Linear coefficient of thermal expansion of fresh ice (CTEFI) is around 5.1 . $10^{-5} \mathrm{~K}^{-1}$.

In general, when saline ice includes permeable channels filled by liquid brine, the mass of a saline ice sample is not a constant, and formula (4) cannot be used for the calculation of VCTE for saline ice. Here, we assume that saline ice consists of ice with closed brine pockets (ICP) and permeable brine channels. ICP is not permeable by brine, and the ICP salinity is constant. Therefore VCTE for ICP is calculated according to formula (4) as follows:

$$
\kappa_{\mathrm{icp}}=-\frac{1}{\rho_{\mathrm{icp}}} \frac{d \rho_{\text {icp }}}{d T} .
$$




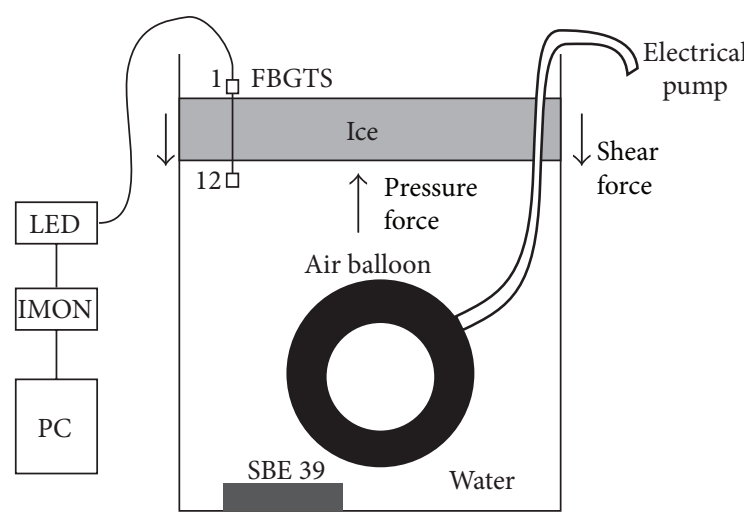

(a)

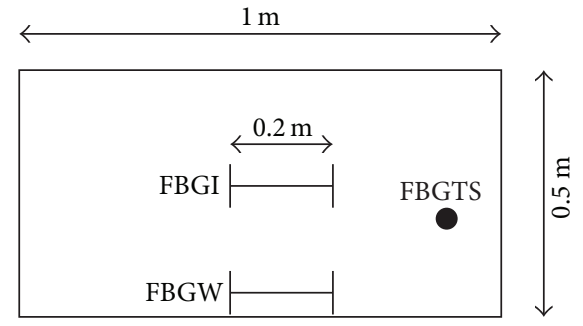

(b)

FIGURE 7: Scheme of the experiment on ice extension due to the water pressure increase in the ice tank (a). Locations of FBG strain sensors on the ice surface (FBGI) and on the tank wall (FBGW) (b).

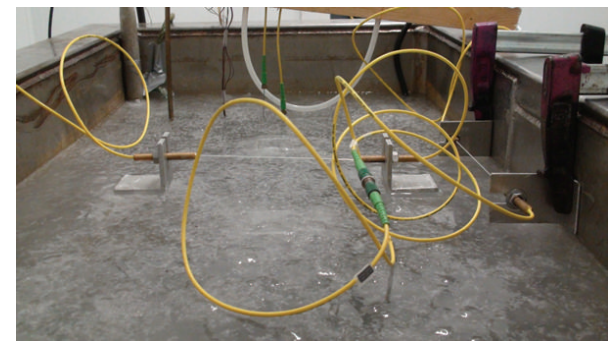

(a)

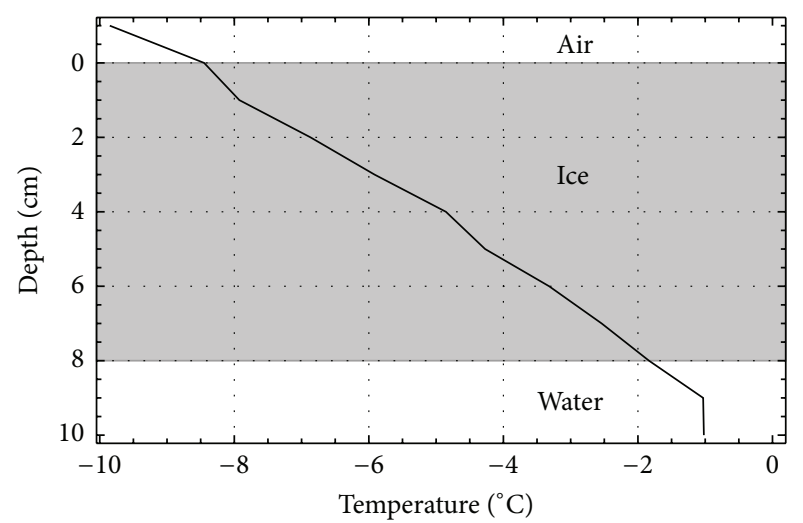

(b)

FIGURE 8: Laboratory experiment in the ice tank (a). Temperature profile in model ice measured with FBG thermistor string (b).

ICP density is calculated by the formula [17]

$$
\rho_{\text {icp }}=\frac{(1-\nu) \rho_{w} \rho_{i} S}{\sigma_{\text {icp }}\left(\rho_{i}-\rho_{w}\right)+\rho_{w} S\left(1-\sigma_{\text {icp }}\right)},
$$

where $\rho_{w}=999 \mathrm{~kg} / \mathrm{m}^{3}$ is the fresh water density, $\sigma_{\text {icp }}$ is the ICP ice salinity, and $S$ is the fractional salt content of the brine. For sea water brine the fractional salt content is calculated with the formulas

$$
\begin{aligned}
& S=\alpha T, \quad \alpha=-0.0182 \mathrm{~K}^{-1}, T \in\left(0^{\circ} \mathrm{C},-8.2^{\circ} \mathrm{C}\right), \\
& S=0.149+(T+8.2) \alpha^{\prime} \\
& \quad \alpha^{\prime}=-0.01^{\circ} \mathrm{C}^{-1}, T \in\left(-8.2^{\circ} \mathrm{C},-23^{\circ} \mathrm{C}\right) .
\end{aligned}
$$

The ICP salinity is equal to the mass of salt in the liquid brine included in closed brine pockets in a unit mass of ICP. VCTE calculated with formulas (6) and (7) coincides with VCTE introduced by Malmgren [4], who assumed that permeable channels are absent in sea ice.

Since saline ice includes ICP and permeable channels filled by liquid brine the total salinity is equal to a sum $\sigma_{\mathrm{si}}=\sigma_{\mathrm{icp}}+\sigma_{\mathrm{pc}}$, where $\sigma_{\mathrm{pc}}$ is a mass of salt in permeable brine channels inside a unit volume of saline ice. Liquid brine located in the permeable channels does not influence the thermal expansion of saline ice [6]. The salinity of the ICP is constant, but the ICP mass is changing since some closed brine pockets can transform into permeable channels due to the temperature changes. Thermal expansion of saline ice is determined by volumetric changes of the ICP which depend on both the thermal and mass changes.

Let us assume that the mass of an infinitesimal ICP sample is $\delta m_{\text {icp }}=\rho_{\text {icp }} \delta V_{\text {icp }}$ when the ICP temperature is $T$. The ratio of the ICP masses related to different temperatures is equal to

$$
\frac{\delta m_{\mathrm{icp}}}{\delta m_{\mathrm{icp}, 0}}=\frac{\rho_{\mathrm{icp}}}{\rho_{\mathrm{icp}, 0}} \frac{\delta V_{\mathrm{icp}}}{\delta V_{\mathrm{icp}, 0}},
$$

where the subscript " 0 " is related to the values of the mass, density, and volume at $T=T_{0}$. Assuming ice isotropy and small deformations we can rewrite formula (9) in the form

$$
\varepsilon_{\delta m}=\frac{\rho_{\text {icp }}}{\rho_{\text {icp }, 0}}\left(1+3 \varepsilon_{\delta L}\right)-1,
$$


where the relative change of the ICP mass $\varepsilon_{\delta m}$ and the linear deformation $\varepsilon_{\delta L}$ are determined by the formulas

$$
\begin{gathered}
\varepsilon_{\delta m}=\frac{\delta m_{\mathrm{icp}}-\delta m_{\mathrm{icp}, 0}}{\delta m_{\mathrm{icp}, 0}}, \\
\varepsilon_{\delta L}=\frac{\delta L_{\mathrm{icp}}-\delta L_{\mathrm{icp}, 0}}{\delta L_{\mathrm{icp}, 0}}
\end{gathered}
$$

where $\delta L_{\text {icp }}$ is a linear dimension of the sample and $\delta L_{\text {icp }, 0}$ is its initial value.

The experiments were performed with ice samples of finite sizes. FBG sensors registered the temperature $T$ and linear deformation $\varepsilon_{L}$ of the samples depending on the time. The linear deformation of a sample is determined by the formula

$$
\varepsilon_{L}=\frac{L(t)-L_{0}}{L_{0}}
$$

where $L$ is the sample length, $L_{0}$ is its initial value, and $t$ is the time.

The effective coefficient of linear thermal expansion (ECTE) of an ice sample is determined by the formula

$$
\kappa_{\mathrm{si}, L}=\frac{d \varepsilon_{L}}{d t}\left(\frac{d T}{d t}\right)^{-1},
$$

where the temperature $T(t)$ is registered in a point inside the sample. Temperature gradients within the sample can make it difficult to analyze (13). Therefore in our experiments we changed the air temperature slowly and measured the temperature with FBG thermistor string at several points within an ice sample to control the temperature gradient over the sample.

A representative time of temperature equilibration over a sample is given by the formula

$$
t_{*}=\frac{\rho_{\mathrm{si}} c_{\mathrm{si}}}{k_{\mathrm{si}}} L_{*}^{2},
$$

where $\rho_{\mathrm{si}}=920 \mathrm{~kg} / \mathrm{m}^{3}$ is typical value of sea ice density, $k_{\mathrm{si}}=$ $2 \mathrm{~W} /(\mathrm{m} \cdot \mathrm{K})$ is a typical value of the thermal conductivity of sea ice, $L_{*}=0.1 \mathrm{~m}$ is representative length of the sample, and $c_{\mathrm{si}}$ is the specific heat capacity of saline ice. The specific heat capacity of fresh ice is equal to $2 \mathrm{~kJ} /(\mathrm{kg} \cdot \mathrm{K})$. Formula (14) then gives a time of temperature equilibration in fresh ice samples of 2.5 hours.

The specific heat capacity of saline ice increases with temperature according to the formula derived by Schwerdtfeger [17]. This is because there is a greater degree of phase change, and thus a greater latent heat expenditure, at higher temperatures. For example, the specific heat capacities of saline ice with salinities $4 \mathrm{ppt}$ and $8 \mathrm{ppt}$ reach, respectively, $10.4 \mathrm{~kJ} /(\mathrm{kg} \cdot \mathrm{K})$ and $18.7 \mathrm{~kJ} /(\mathrm{kg} \cdot \mathrm{K})$ when the temperature is $-3^{\circ} \mathrm{C}$. With these salinities, the times of temperature equilibration reach, respectively, 13 hours and 23.4 hours.

The relative change of the ICP mass $\varepsilon_{m}$ in a sample is estimated with a formula similar to (10):

$$
\varepsilon_{m}=\frac{\rho_{\text {icp }}}{\rho_{\text {icp }, 0}}\left(1+3 \varepsilon_{L}\right)-1 .
$$

Results of the long-term tests with fresh ice samples are shown in Figure 9. The temperature change interval was 45 hours. Figure 9(a) shows temperature variations in the ice samples as measured with the FBG thermistor string. The insert graph on Figure 9(a) shows temporal variations induced by the cooling cycle of the fans. The data are averaged over $15 \mathrm{~min}$ intervals to minimize the influence of the fan cycle. Calculated values for ECTE for fresh ice are shown in Figure 9(b), and these are close to the CTEFI shown by the dashed line, with deviation less than $10 \%$.

Two mixtures of sea water and fresh water were made, with respective salinities $9.4 \mathrm{ppt}$ and $2.3 \mathrm{ppt}$. These two mixtures were frozen and prepared as ice samples: results for these samples are shown in Figures 10-12. The experiments lasted for $190 \mathrm{~h}$ and $415 \mathrm{~h}$, respectively. The temperature and strain are shown as a function of time in Figure 10. Strain is initially defined as zero. In Figure 10(a) the strain and temperature gradients have opposite signs between 50 and $100 \mathrm{~h}$. In Figure 10(b) the gradients have the same sign throughout. The opposite gradients of strain in Figure 10(a) show the temperature range in which saline ice exhibits abnormal thermal expansion.

The dependency of strain on temperature is shown in Figures 11(a) and 11(b). The circles indicate the beginning of the experiments. Abnormal thermal expansion (the ice contracts with increasing temperature) is seen above around $-10^{\circ} \mathrm{C}$ in Figure 11(a) (which shows the test conducted on ice made with water of $9.4 \mathrm{ppt}$ salinity). The less saline sample also shows a slightly nonlinear, but still positive, ECTE (Figure 11(b)). In both of the experiments hysteresis was observed in the strain-temperature curves at the points where the cycle switches from heating to cooling: similar effects were observed by Butkovich [7] and Johnson and Metzner [5]. Figures $11(\mathrm{c})$ and $11(\mathrm{~d})$ show the relative changes of the ICP masses $\varepsilon_{m}$ in the ice samples calculated with formula (15). One can see that the ICP mass decreases with the temperature increase in the sample with salinity $9.4 \mathrm{ppt}$. The ICP mass of the sample with salinity $2.3 \mathrm{ppt}$ changes in the opposite direction. Repeating thermal loading leads to the loss of the ICP mass in both cases. This suggests that thermal cycling tends to promote open channels in the ice in favour of closed brine pockets.

Dependencies $\varepsilon_{L}(T)$ calculated from the experimental data were approximated by polynomial fit on different time intervals, to allow the calculation of the ECTE by formula (13). Examples of polynomial approximations are shown in Figure 12(a), and Figure 12(b) shows the ECTE versus the temperature. The black squares show the ECTE calculated by Johnson and Metzner [5] with an ice salinity of 2 ppt.

ECTEs calculated with using of the data of the long-term (the temperature change interval is 2-3 hours), short-term, and monotonic tests with saline ice samples are compared in Figure 13(a). In all these tests ice samples were made from a mixture of sea and fresh water of $6 \mathrm{ppt}$ salinity. Averaging of the strain-temperature curves over $15 \mathrm{~min}$, and polynomial interpolation of these averages, was used to calculate ECTE on specific time intervals. Their duration was 11 hours in the long-term test, 2 hours in the short-term test, and 8 hours in the monotonic test. The long-term test shows abnormal 


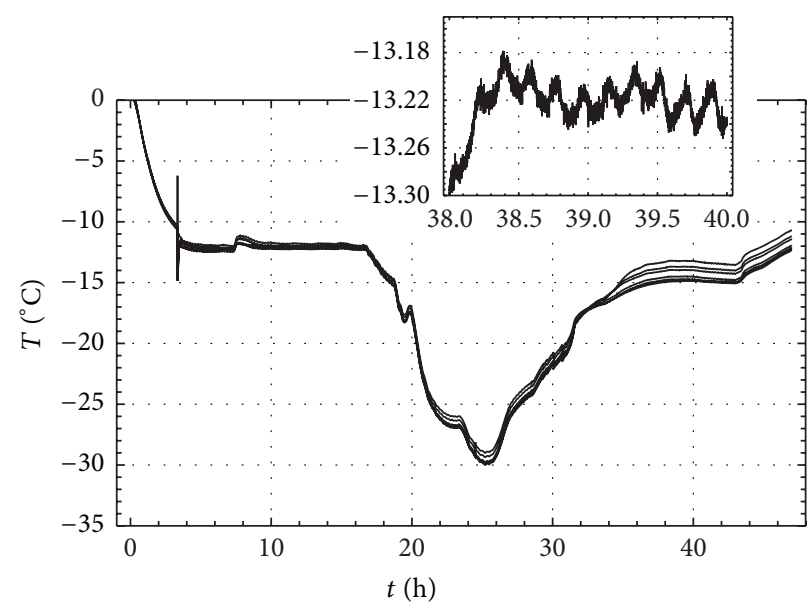

(a)

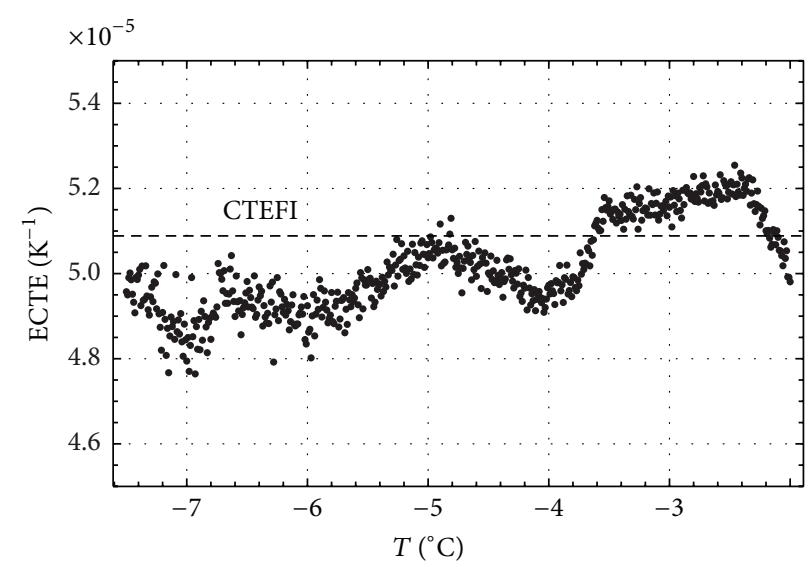

(b)

FIGURE 9: Temperature (a) and the coefficient of thermal expansion versus the time (b), for fresh ice sample in long-term test.

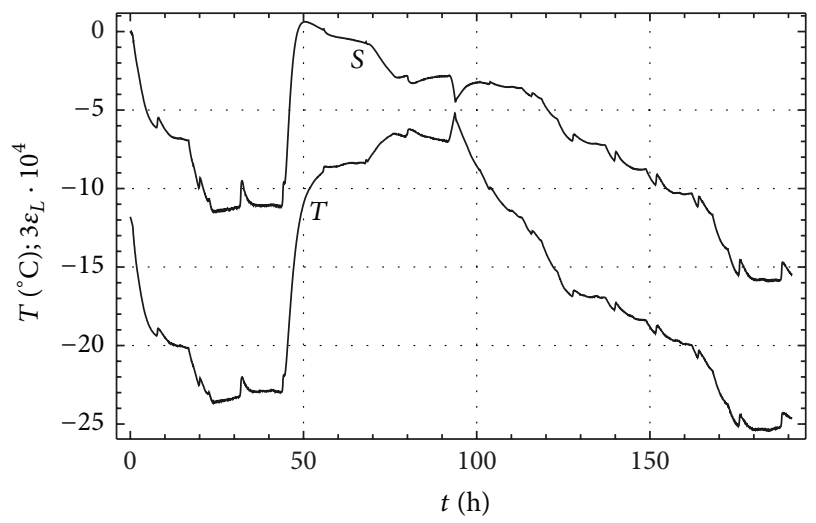

(a)

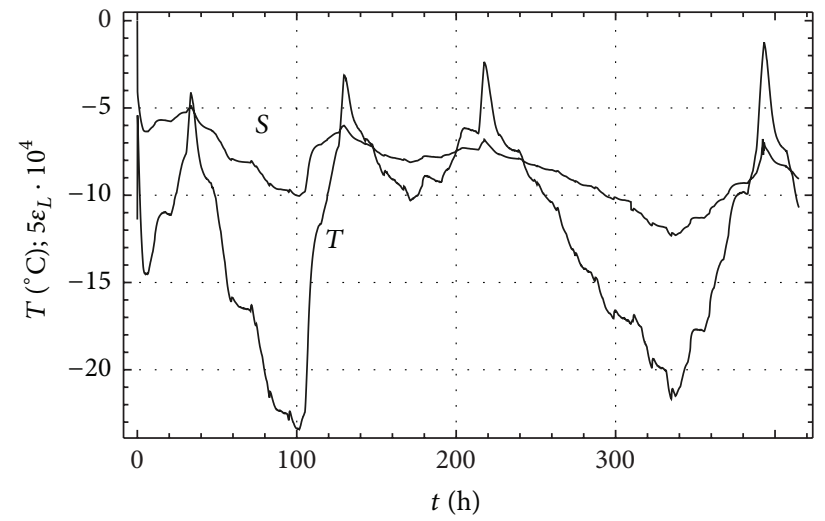

(b)

Figure 10: Temperature $(T)$ and strain $(S)$ versus the time in ice samples with salinities 9.4 ppt (a) and 2.3 ppt (b). Long-term tests.

thermal expansion, with a negative ECTE, when the ice temperature is higher than $-6^{\circ} \mathrm{C}$. Short-term and monotonic tests show normal thermal expansion, with a positive ECTE decreasing with the temperature increase. Figure 13(b) shows similar increase of the ICP mass of the samples with the temperature increase in all three tests.

4.2. Thermal Expansion of Confined Ice. In total, 27 tests were conducted on confined ice, across the three geometries shown in Figure 5, and for both fresh and saline ice (i.e., 6 different experimental configurations). These experiments took place in the cold rooms of University College London. Due to the complications of sharing working spaces and running long experiments (often $>24 \mathrm{~h}$ ), tests were not conducted according to a rigorous schedule but rather on an ad hoc basis which allowed for both warming and cooling to be investigated in all configurations.

Figure 14 shows the results of a typical experiment. The measured strain and temperature are calculated directly from the fiber Bragg wavelengths, using known calibration coefficients and measured wavelengths for the thermistors submersed in $0^{\circ} \mathrm{C}$ iced water. These measurements are shown in Figures 14(a) and 14(b). In the temperature plot we can see two minor sources of error: variations in the air temperature due to the cold room fan cycle (duration of 5 minutes) and a sudden cooling (just after 02.00) when the door to an adjoining cold room was opened. Neither of these processes has a strong effect on the observed in-ice temperatures (the lowest six lines on the top right plot) but both will have some effect on overall results.

Calculated ECTEs are shown in Figures 14(c) and 14(d). For these, ice temperature and strain are averaged over $600 \mathrm{~s}$ periods. If the temperature difference in this window is less than $0.1^{\circ} \mathrm{C}$ then the measurement is ignored, since slight residual strains at constant temperatures can lead to high anomalous expansion coefficients. The results shown are therefore those for which the temperature difference across the measurement window was sufficiently high. These are then shown as a function of time and temperature.

Figure 15 shows results combined across all experiments. For fresh ice (Figure 15(a)) there is a range of positive values of ECTE, with a few negative outliers. We see no clear trend with 


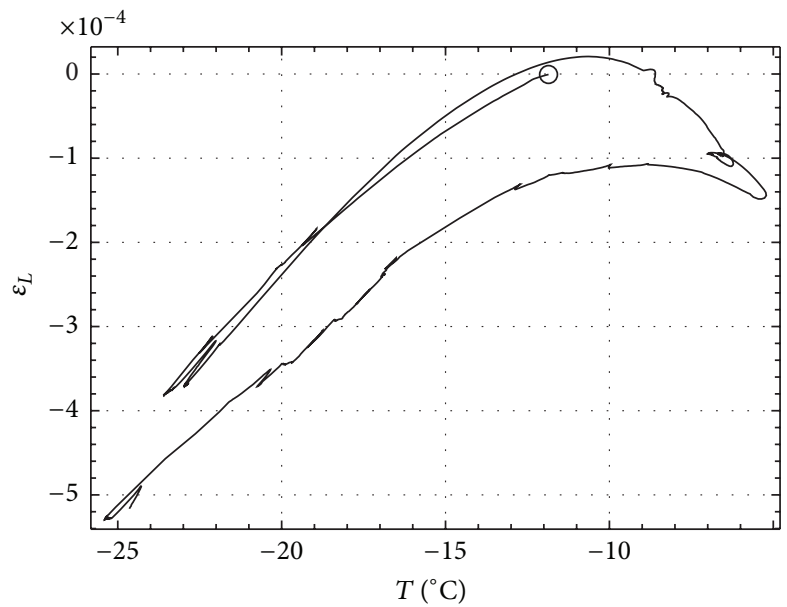

(a)

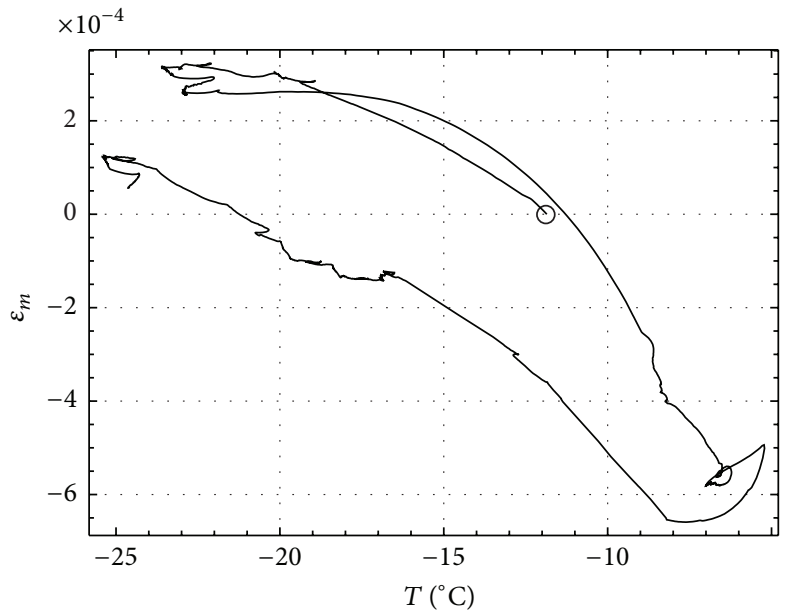

(c)

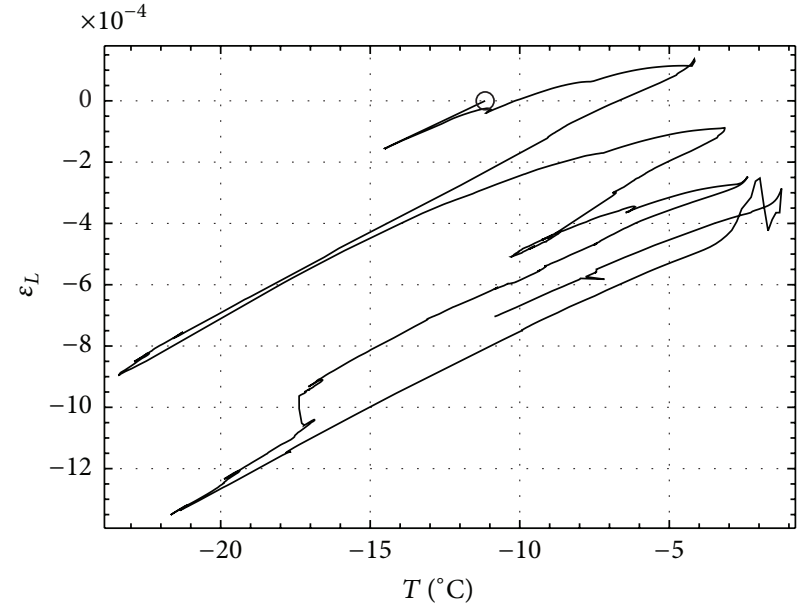

(b)

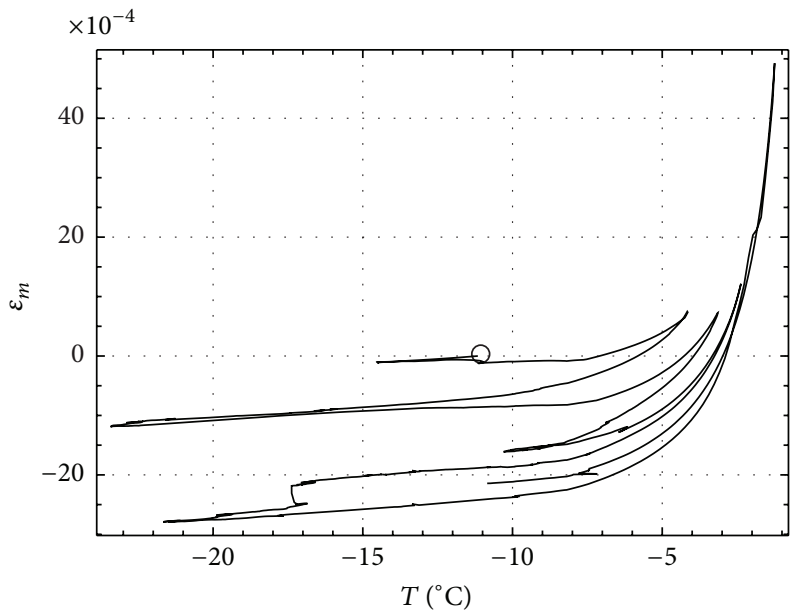

(d)

FIGURE 11: Strains versus temperature in ice samples with salinities $9.4 \mathrm{ppt}$ (a) and $2.3 \mathrm{ppt}$ (b) and the relative changes of the ICP masses of the samples with salinities $9.4 \mathrm{ppt}(\mathrm{c})$ and $2.3 \mathrm{ppt}(\mathrm{d})$ versus temperature. Long-term tests.

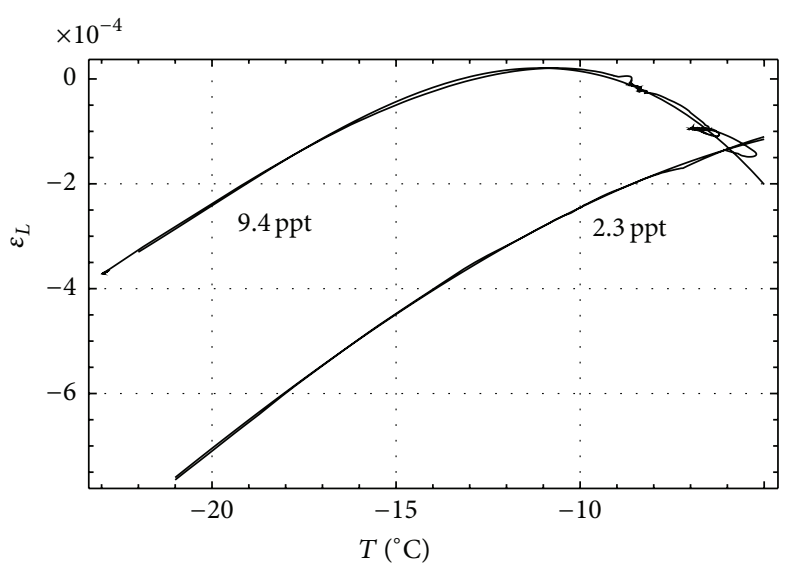

(a)

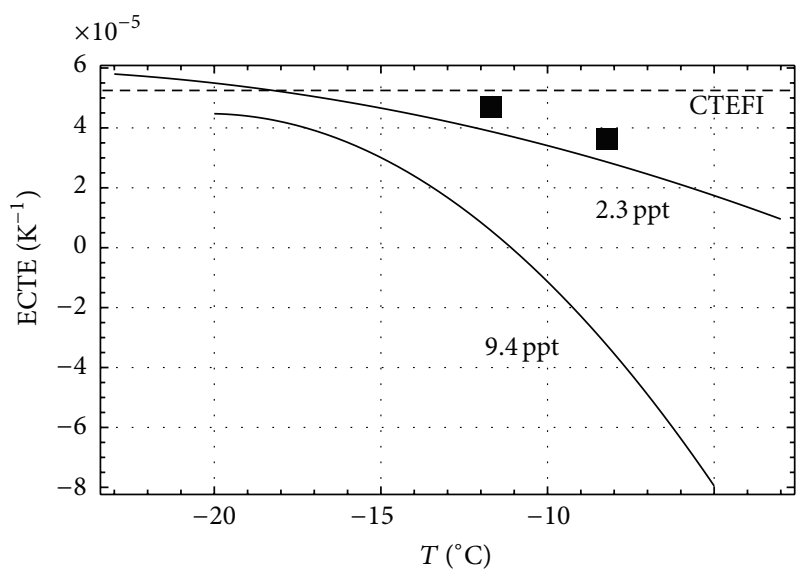

(b)

FIGURE 12: Polynomial approximations of the strain-temperature dependencies of ice samples (a) and ECTE versus the temperature calculated for the same samples (b). The curves are constructed with initial ice salinities $9.4 \mathrm{ppt}$ and $2.3 \mathrm{ppt}$. Long-term tests. 


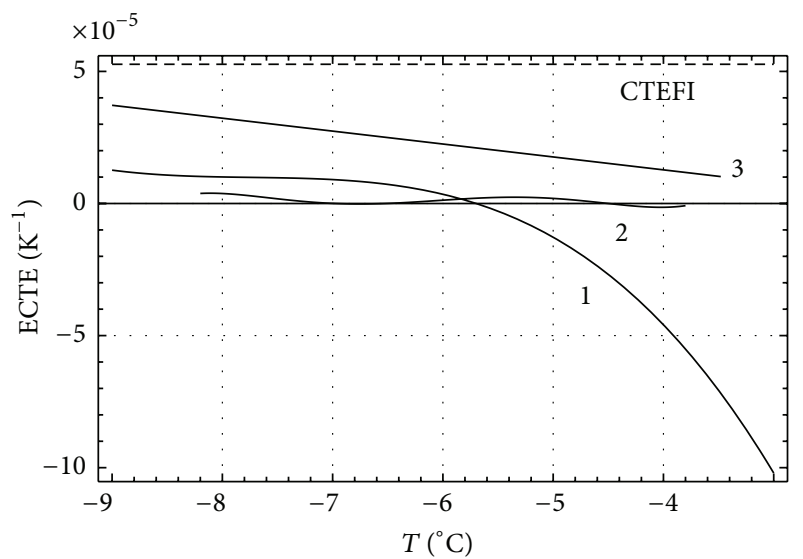

(a)

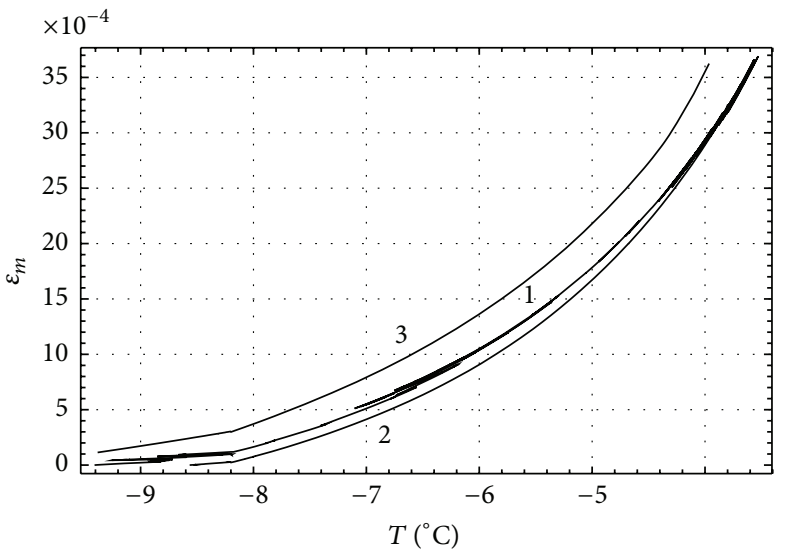

(b)

FIGURE 13: ECTE (a) and the ICP masses (b) versus the temperature in long-term (1), short-term (2), and monotonic (3) tests with saline ice samples. The ice salinity is $6 \mathrm{ppt}$.

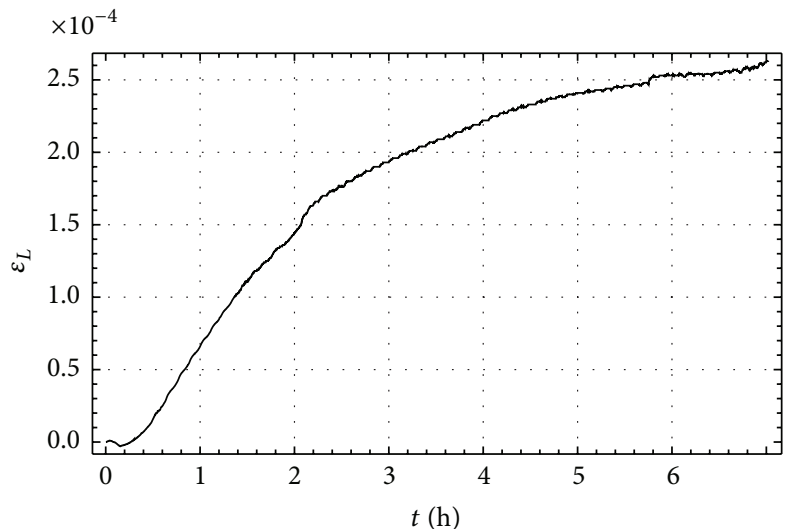

(a)

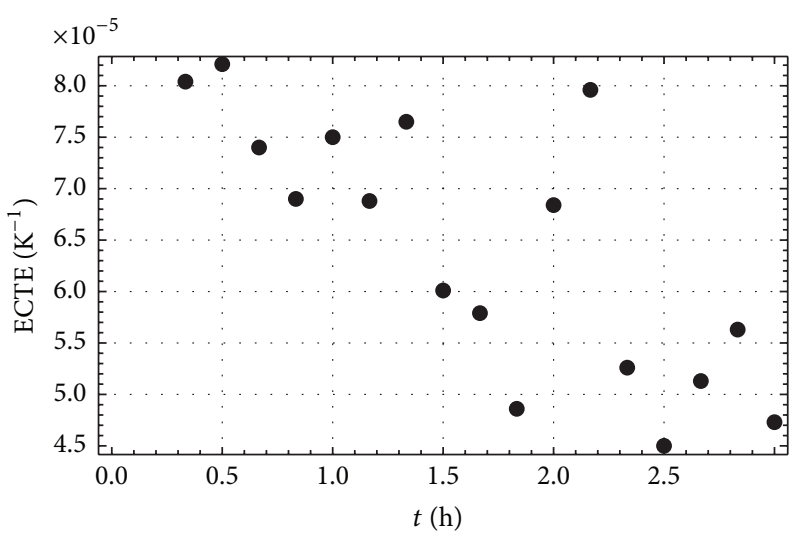

(c)

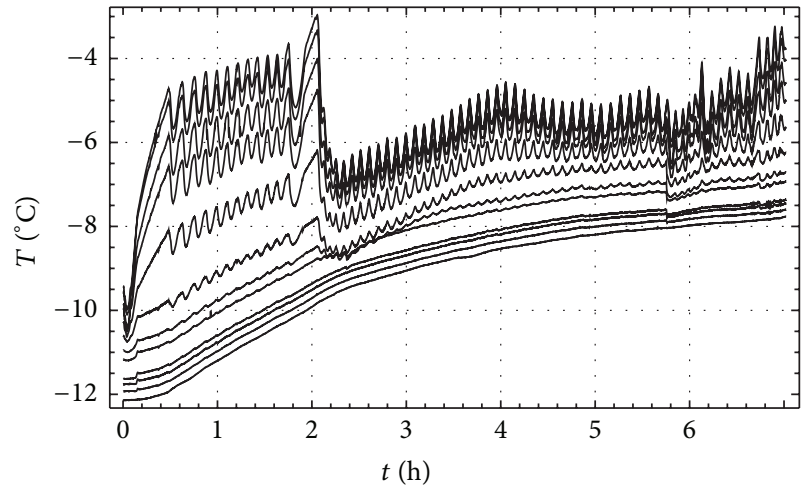

(b)

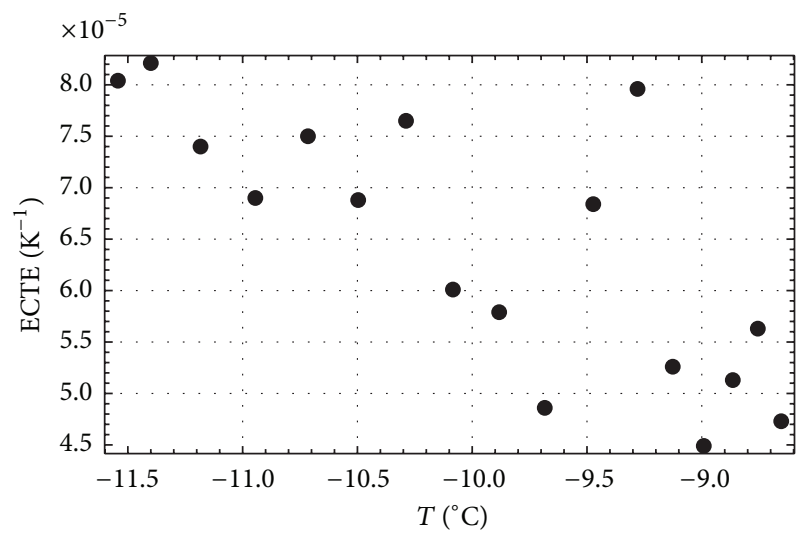

(d)

FIGURE 14: Results from a typical thermal expansion experiment. Strain (a) and temperature (b) measurements are shown versus the time. Calculated ECTEs are shown as a function of time (c) and temperature (d). The results shown are for unconstrained fresh ice.

temperature. Average ECTEs are $4.69 \times 10^{-5} \mathrm{~K}^{-1}$ for unconstrained fresh ice, $2.69 \times 10^{-5} \mathrm{~K}^{-1}$ for ice constrained by an external pipe, and $6.43 \times 10^{-5} \mathrm{~K}^{-1}$ for ice constrained by both internal and external pipes. The average for the unconstrained pipe is within $10 \%$ of the literature value. For saline ice with no pipe (average value $5.24 \times 10^{-5} \mathrm{~K}^{-1}$ ) and with 1 pipe (average $5.06 \times 10^{-5} \mathrm{~K}^{-1}$ ) we see similar behavior. For saline ice (Figure 15(b)) with two pipes the values over the first eight hours of the test are similar (average $5.42 \times 10^{-5} \mathrm{~K}^{-1}$ ), but then we see a clear trend towards negative ECTE with 


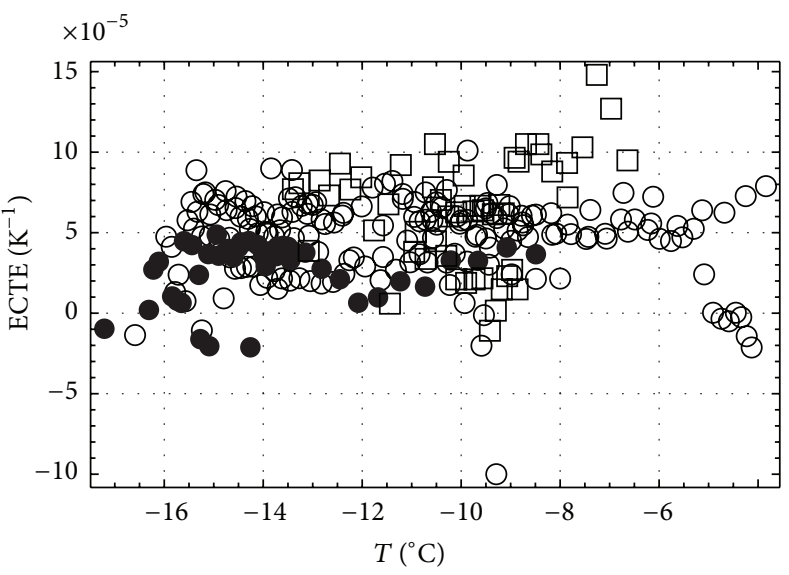

(a)

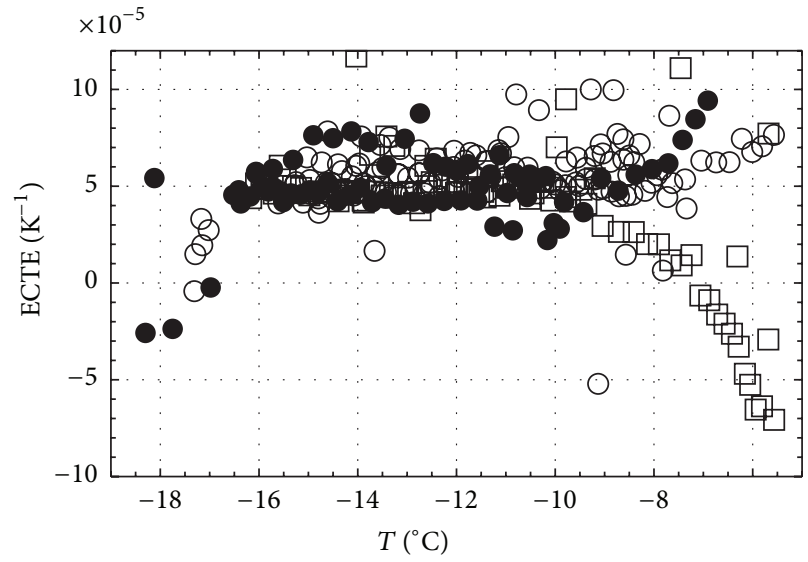

(b)

FIGURE 15: Experimentally measured ECTE, plotted as a function of temperature for fresh ice (a) and for saline ice (b). I: unconstrained sample, shown by unshaded circles; II: sample with one pipe, shown by shaded circles; and III: sample with two pipes.

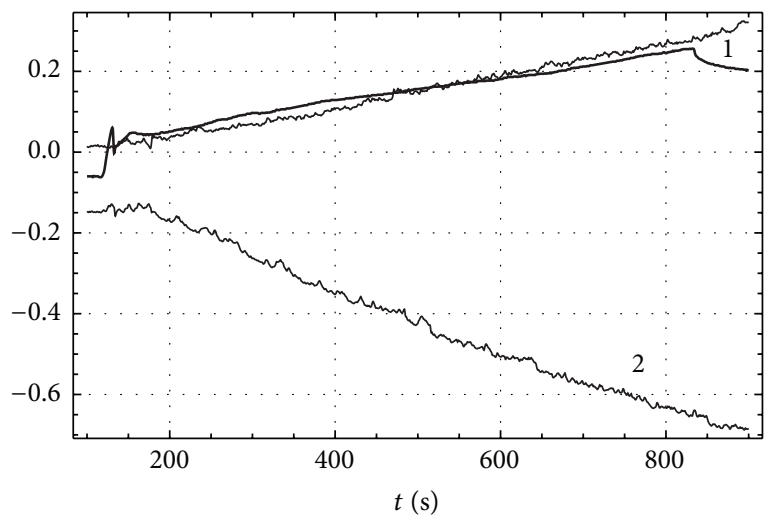

_ Pressure, dbar
1: ice strain, millistrain
2: tank wall strain, millistrain

(a)

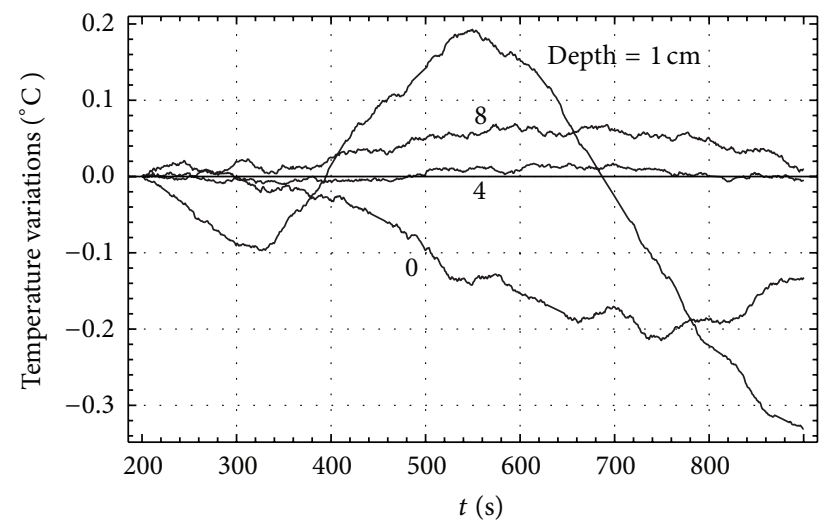

(b)

Figure 16: Strains in ice and tank walls induced by the increase of the water pressure below the ice (a). Temporal variations of the ice temperature induced by brine migration through the ice (b).

rising temperature (above around $-10^{\circ} \mathrm{C}$ ). It may be that the dual pipes prevent brine drainage, and the phase changes associated with trapped brine drive the negative thermal expansion coefficient. The conditions at the surface of the ice can affect thermal expansion by constraining the ice as well as by constraining the brine. We believe that the high scatter seen in our results may be due to residual stresses which build up and relax in the ice over time, particularly as it sticks against the pipes. These residual stresses may be released later than they build up, which would mean that the correlation between observed ice strain and instantaneous temperature is less clear than if all strains are realized immediately.

4.3. Thermal Expansion of Floating Confined Ice. The effects of under-ice pressure on a confined ice sheet are shown in Figure 16. As the pressure was gradually increased in the water, the strain in the ice also increased (Figure 16(a)). At the same time the strain measured on the inside face of the wall decreased, indicating that the wall bent outwards slightly. The temperature at $1 \mathrm{~cm}$ depth and deeper increased as a result of water migrating through the ice sheet (Figure 16(b)). This water migration was also visually observed. The decrease in the surface temperature is related to the overall temperature changes in the cold lab. This effect is also picked up by the thermistor at a depth of $1 \mathrm{~cm}$, after around $500 \mathrm{~s}$.

Figure 16(a) shows positive thermal expansion of ice caused by the vertical migration of liquid brine through the ice (which has a vertical temperature gradient). Under-ice pressure drives the brine upwards. The brine temperature is initially equal to the temperature of its surrounding ice, since the brine is in local thermodynamic equilibrium with ice. Therefore, as brine migrates upward, warmer brine from the bottom of the ice (where the ice is warmest) heats up the top layers of the ice. From Figure 16, ice deformation reaches 
about $2 \cdot 10^{-4}$ when the temperature increases by about $0.1^{\circ} \mathrm{C}$. This deformation is caused by thermal expansion of ice and ice compression between the tank walls. The conclusion here is that if brine is forced vertically upwards through the ice, this is likely to warm the ice (since the sea water and lower brine are warm compared to the brine near the upper surface), leading to an expansion.

\section{Conclusions}

FBG sensors are a productive tool for laboratory measurements of the thermomechanical properties of saline ice. It was possible to perform experiments with samples of different sizes and geometries. The high sampling frequency, accuracy, and resolution of the FBG sensors provided good quality data across a temperature range from $0^{\circ} \mathrm{C}$ to $-20^{\circ} \mathrm{C}$. The sensors, and their associated hardware and software, were stable and robust. The main complication in these experiments was in developing techniques to mount the FBG sensors onto the ice samples.

In this paper we have compared values of the coefficients of linear thermal expansion calculated from laboratory experiments (ECTE) to predictions based on a model of ice as an impermeable medium (to liquid brine) and on a fresh ice model. Negative values of ECTE were found when the ice samples had salinities of $6 \mathrm{ppt}, 8 \mathrm{ppt}$, and $9.4 \mathrm{ppt}$. Abnormal thermal expansion, contraction with increasing temperature, was observed at temperatures higher than $-8^{\circ} \mathrm{C}$ (6 ppt and 8 ppt experiments) or $-11^{\circ} \mathrm{C}$ (9.4 ppt experiments). Hysteresis effects, similar to those described in earlier work, were observed. Surface area to volume ratio and confinement of the ice appear to affect the ECTE. In experiments with confined floating ice we observed the heating and thermal expansion of ice due to the vertical migration of liquid brine through the ice under the action of water pressure beneath the ice.

We formulated a new model of saline ice consisting of the ice with closed brine pockets (ICP) and permeable brine channels and assumed that closed brine pockets can transform into permeable channels under temperature changes. This process may influence the fraction of the mass contained in closed pockets (the ICP mass). Using experimental data we estimated changes of the ICP mass of the ice samples with different salinity. It was discovered that the ICP mass decreases with increasing temperature in ice samples of high salinity (9.4 ppt), and the ICP mass increases with increasing temperature in ice samples with salinities $6 \mathrm{ppt}$ and 2.3 ppt. Repeated or cycling temperature changes influence the decrease in ICP mass with time in all samples.

\section{Conflict of Interests}

The authors declare that there is no conflict of interests regarding the publication of this paper.

\section{Acknowledgment}

The authors wish to acknowledge the support of the Research Council of Norway through SFI SAMCoT.

\section{References}

[1] W. F. Weeks and S. F. Ackley, "The growth, structure and properties of sea ice," in The Geophysics of Sea Ice, N. Untersteiner, Ed., pp. 9-164, Plenum Press, New York, NY, USA, 1986.

[2] K. M. Golden, H. Eicken, A. L. Heaton, J. Miner, D. J. Pringle, and J. Zhu, "Thermal evolution of permeability and microstructure in sea ice," Geophysical Research Letters, vol. 34, no. 16, Article ID L16501, 2007.

[3] O. Petterson, "On the properties of water and ice," in VegaExpeditionens Veisnskapliga Iakttagelser, Nordenskiold, Ed., vol. 2, pp. 247-323, F. \& G. Beijers Förlag, Stockholm, Sweden, 1883.

[4] F. Malmgren, "On the properties of sea ice," in The Norwegian North Polar Expedition with the "Maud", 1918-1925, vol. 1, no. 5, 1927.

[5] J. B. Johnson and R. C. Metzner, "Thermal expansion coefficients for sea ice," Journal of Glaciology, vol. 36, no. 124, pp. 343349, 1990.

[6] G. F. N. Cox, “Thermal expansion of saline ice," Journal of Glaciology, vol. 29, no. 103, pp. 425-432, 1983.

[7] T. R. Butkovich, "Thermal expansion of ice," Journal of Applied Physics, vol. 30, no. 3, pp. 350-353, 1959.

[8] A. Marchenko, T. Thiel, and S. Sukhorukov, "Measurements of thermally induced deformations in saline ice with fiber Bragg grating sensors," in Proceedings of the 21st IAHR International Symposium on Ice "Ice Research for a Sustainable Environment", Z. Li and P. Lu, Eds., Dalian University of Technology Press, Dalian, China, June 2012.

[9] A. Marchenko, D. Wrangborg, and T. Thiel, "Using distributed optical fiber sensors based on FBGs for the measurement of temperature fluctuations in saline ice and water on small scales," in Proceedings of the 22nd International Conference on Port and Ocean Engineering under Arctic Conditions (POAC '13), p. 11, Espoo, Finland, June 2013.

[10] B. Lishman and A. Marchenko, "An investigation of relative thermal expansion and contraction of ice and steel," in Proceedings of the 22nd IAHR International Symposium on Ice, paper 1173, Singapore, 2014.

[11] D. Wrangborg and A. Marchenko, "Measurement of loads exerted by sea ice on the quay at kapp Amsterdam on svalbard," Tech. Rep. POAC15-141, Trondheim, Norway, 2015.

[12] A. Othonos and K. Kalli, Fiber Bragg Gratings: Fundamentals and Applications in Telecommunications and Sensing, Artech House, 1999.

[13] Y. J. Rao, "In-fibre Bragg grating sensors," Measurement Science and Technology, vol. 8, no. 4, pp. 355-376, 1997.

[14] P. Ferraro and G. De Natale, "On the possible use of optical fiber Bragg gratings as strain sensors for geodynamical monitoring," Optics and Lasers in Engineering, vol. 37, no. 2-3, pp. 115-130, 2002.

[15] B. Mueller, J. Meissner, and T. Thiel, Results of Continuous InSitu Stress Measurement with Optical Strain Sensors, Taylor \& Francis, London, UK, 2006.

[16] E. R. Pounder, The Physics of Ice, Pergamon Press, Oxford, UK, 1965.

[17] P. Schwerdtfeger, “The thermal properties of sea ice," Journal of Glaciology, vol. 4, no. 36, pp. 789-807, 1963. 


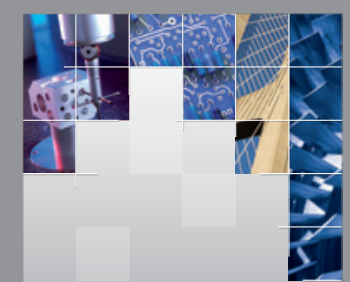

\section{Enfincering}
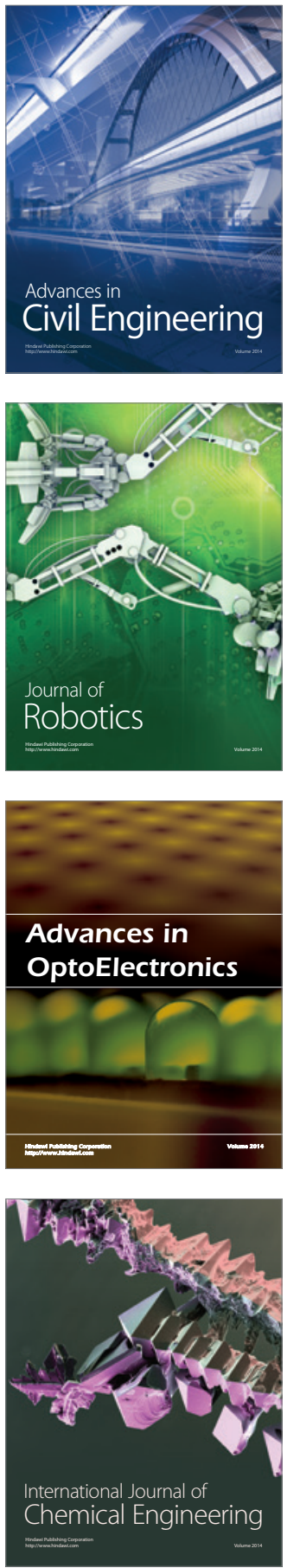

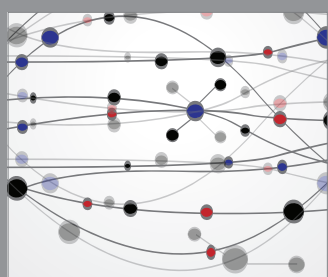

The Scientific World Journal

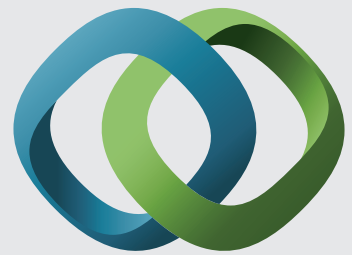

\section{Hindawi}

Submit your manuscripts at

http://www.hindawi.com
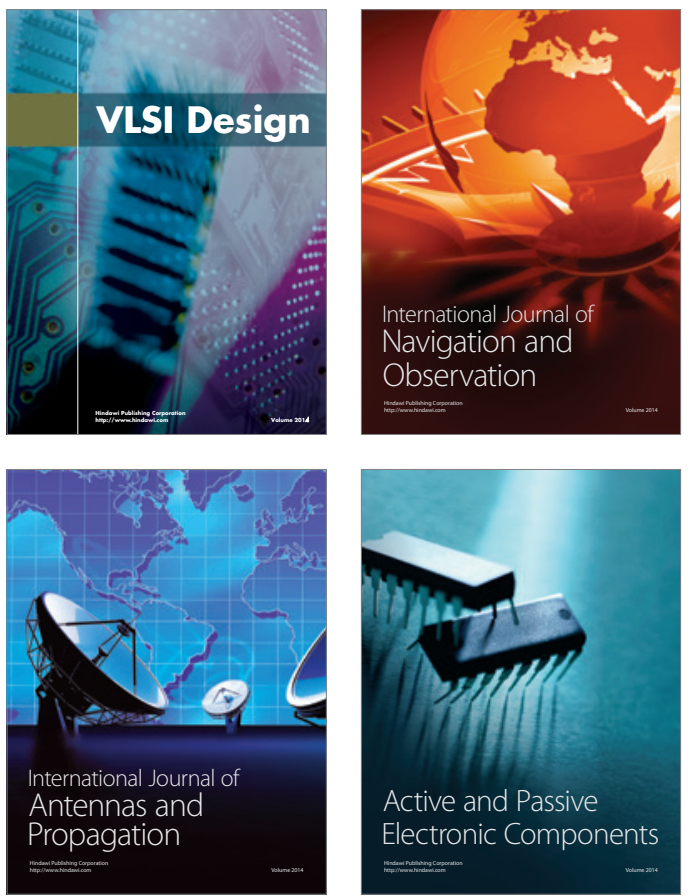
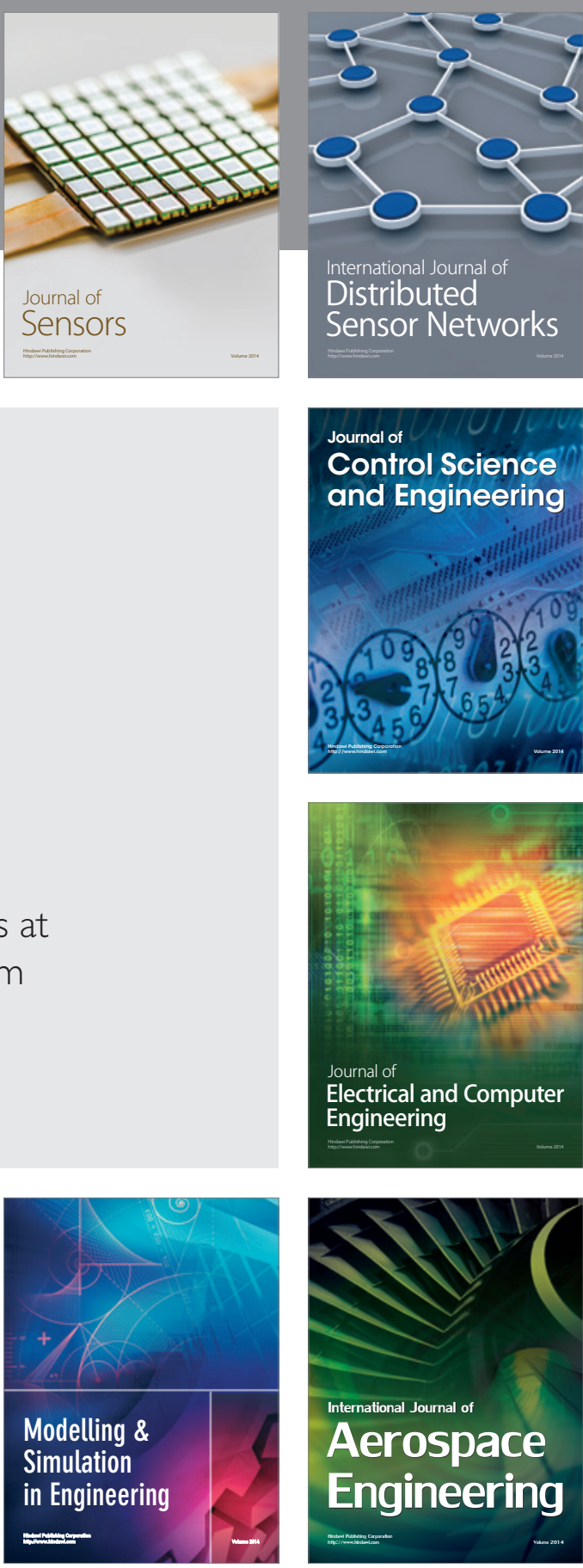

International Journal of

Distributed

Sensor Networks

Journal of

Control Science

and Engineering
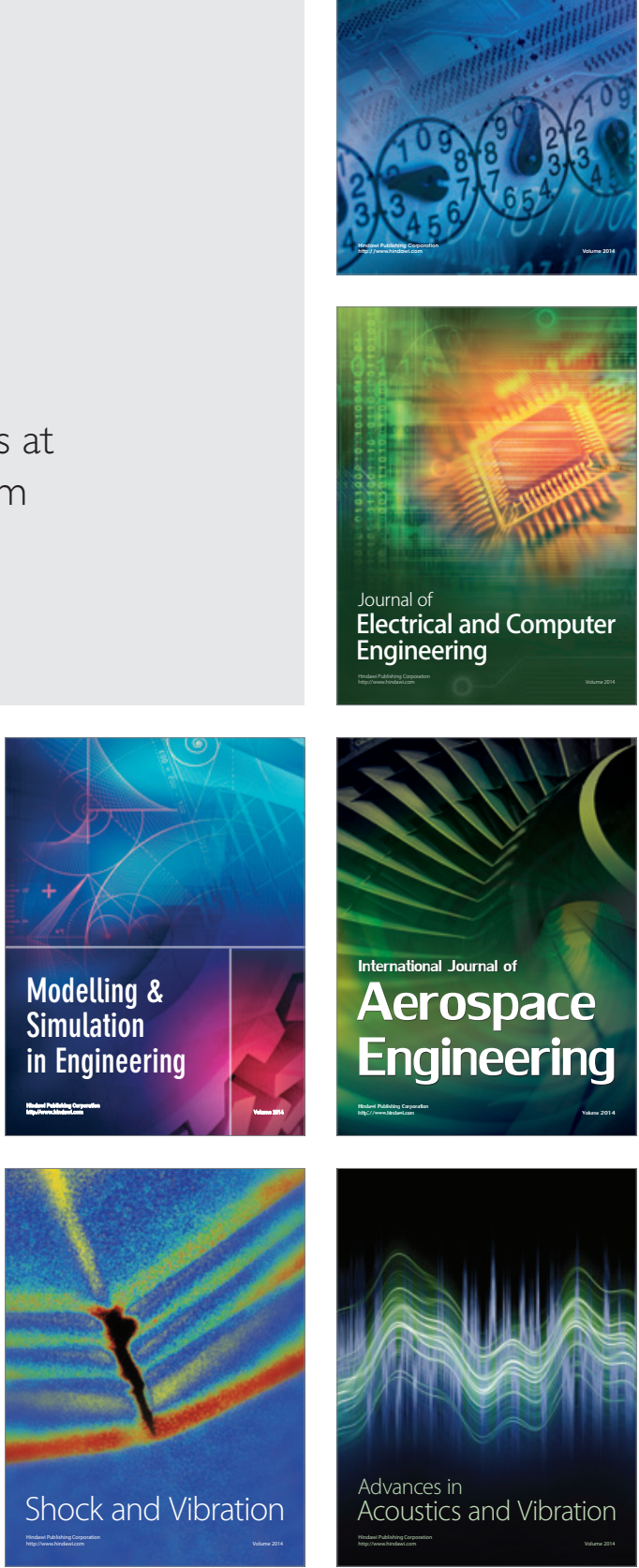